\title{
Trabalho análogo ao de escravo e as políticas públicas voltadas para o mercado de trabalho: solução ou manutenção do problema
}

Resumo: $O$ presente artigo tem como objetivo a discussão sobre o trabalho análogo ao de escravo no Brasil e suas principais políticas públicas de combate a esse fenômeno, principalmente via mercado de trabalho. Para tanto, foram realizados estudo qualitativo sobre o tema, analisando bases de dados de vários órgãos internacionais e nacionais que tratam das condições laborais, e revisão bibliográfica, para discutir a efetividade das políticas públicas. Os resultados verificados demonstram que os modelos adotados de combate à escravidão contemporânea não vêm obtendo êxito, ao longo dos últimos 15 anos. Com isso, percebe-se que essas políticas públicas devem mudar de eixo mercado de trabalho e pensar em alternativas de enfrentamento.

Palavras-chave: Mercado de Trabalho. Políticas Públicas. Trabalho análogo ao de escravo.

Slave analogous labor and public policies aimed at the labor market: solution or maintenance of the problem

\begin{abstract}
This article aims to discuss the analogous of slave labor in Brazil and its main public policies to combat this phenomenon, mainly through the labor market. To this end, a qualitative study was conducted on the subject, analyzing databases from various international and national bodies dealing with labor conditions, and a literature review to discuss the effectiveness of public policies. The results show that the models adopted to combat contemporary slavery have not been successful over the last 15 years. Thus, it is clear that these public policies must change the labor market axis and think of other coping alternatives.
\end{abstract}

Keywords: Analogous slave labor, Labor Market, Public policies.

\section{Introdução}

O trabalho escravo ainda é uma prática em todo o mundo, constituindo-se um fenômeno global, apesar de ser criminalizado e ter sido abolido desde o século XIX no globo (ALMEIDA, 2010; MAESTRI, 2005). O trabalho análogo ao de escravo se caracteriza pelo atentado à dignidade da pessoa humana, seja de forma direta ou indireta, apresentando diversas formas de

\footnotetext{
1 Graduada em ciências econômicas pela Universidade Federal da Bahia (UFBA). Mestranda em Economia do Desenvolvimento pela Universidade Federal da Bahia (UFBA), do Programa de Pós-Graduação de Economia (PPGE) e Bolsista do Grupo de Pesquisa em Política e Desenvolvimento (Gepode) - "Projeto Vida Pós Resgate". E-mail: marileidesilva_04@hotmail.com.
} 
exploração do trabalho, quer sejam antigas, quer sejam novas (CONFORTI, 2017; OLIVEIRA et al, 2015). Tal prática, apesar de haver leis que expressem sua proibição, possui registro dos países mais ricos aos mais pobres, não sendo exclusividade nas economias em desenvolvimento.

A maioria dos estudos sobre a temática dedica-se sobre as questões da ilegalidade e da sua expansão no mundo, realizando análises mais jurídicas e com cerne nas políticas públicas formuladas com intuito de enfrentamento a essa prática. Em geral, os países são responsáveis pela elaboração de ordenamentos jurídicos e legislativos de combate ao trabalho análogo ao de escravo, tendo como base as recomendações e as Convenções da Organização Internacional do Trabalho (OIT) que tratam sobre trabalho escravo contemporâneo.

No Brasil, na última década, estudiosos do direito do trabalho vêm se debruçando sobre esse objeto, tanto que alguns dos estudos mais recentes são dessa área. Os fatores mais recorrentes encontrados na maioria dos estudos no país estão voltados para a extensão do problema, para as políticas públicas de confronto a essas práticas e a reincidência de trabalhadores nessa situação de exploração extrema.

Para Fujiwara e Silva (2016), a maioria das políticas públicas desenvolvidas, seja no âmbito internacional ou nacional, tem caráter de coerção e repressão, na tentativa de inibir e coibir os infratores. No que tange aos trabalhadores ou às pessoas consideradas em situação de vulnerabilidade, essas políticas possuem caráter qualitativo e de reinserção no mercado de trabalho, ou seja, resolução via políticas neoclássicas.

Diante disso, este texto tem como objetivo apresentar argumentos que refutam a ideia de que o mercado de trabalho formal é a solução no combate ao trabalho análogo ao de escravo, ou seja, as políticas públicas de enfrentamento podem e devem pensar que a qualificação, ser empregável, não evita que as pessoas sejam submetidas a ele, já que o mercado de trabalho acompanha as oscilações econômicas de expansão e de contração.

Foi realizada uma revisão bibliográfica com uma abordagem qualitativa sobre o trabalho análogo ao de escravo no mundo e no Brasil e as políticas públicas brasileiras de combate visam ao mercado de trabalho, e uma análise qualitativa dos dados da OIT, da Secretaria de Inspeção do Trabalho (SIT) vinculada ao Ministério da Economia, do Ministério Público do Trabalho, do Projeto Ação Integrada e do Observatório Digital do Trabalho Escravo no Brasil.

Além dessa breve introdução, o artigo é composto de mais três seções. A primeira contextualiza o trabalho análogo ao de escravo no mundo e no Brasil. A segunda traz em discussão as políticas públicas voltadas para o mercado de trabalho enquanto solução do problema, e a última, as considerações finais sobre a temática. 


\section{Contexto mundial e brasileiro}

O ato de escravizar um ser humano é uma prática antiga, conhecida como escravidão clássica ou antiga (TRESPACH, 2018), e tinha como principal característica a relação posse/propriedade de uma pessoa pela outra (GUARINELLO, 2006). Possuía um cunho legal e havia uma distinção sobre quem poderia ser escravizado ou não, a saber, perdedores de guerra, uso da raça como diferenciador, imigrante e outros (MAESTRI, 2005). No entanto, hoje esse fenômeno possui características do modo de produção vigente, o capitalismo, em que o trabalhador troca sua força de trabalho por um salário que deveria garantir a sua reprodução física e social.

O capitalista, dentro do atual sistema de produção, tem como objetivos principais a busca pelo lucro e o aumento da sua taxa de lucro. Para obtenção desses, enxerga o trabalhador como um insumo na sua função de produção que deve ser expropriado ao máximo, mesmo que atente para a dignidade, a segurança, a saúde, o bem estar, os limites físicos desse, independente de cor, raça, local, religião e outros (FILGUEIRAS, 2015; TIMÓTEO, 2015).

O fator determinante para que uma pessoa se submeta a situação análoga ao de escravo é a vulnerabilidade socioeconômica da mesma (BALES, 2004; OLIVEIRA et al, 2015). Quando um ser humano se encontra em situação de vulnerabilidade econômica, social, educacional, sem recursos para viver de forma digna, o que prevalece é o instinto de sobrevivência, as condições biológicas humanas, o não querer e nem poder passar fome se se sobrepõe, o viver como cidadão fica em segundo plano (OLIVEIRA et al, 2015). Para Oliveira et al (2015), o aumento do arcabouço legal e de combate ao trabalho análogo ao de escravo é fruto de denúncias e pressões sociais, principalmente no Brasil que teve com caso emblemático o de José Pereira ${ }^{2}$.

O trabalho análogo ao de escravo deve ser entendido como toda e qualquer forma de exploração extrema do trabalho e que atente contra a dignidade humana em nome e pela busca de maior taxa de lucro. Logo, esse fenômeno tem em si uma complexidade e não pode ser entendido apenas como uma forma de coerção direta e forçada, pois não é necessária a presença de "grilhões" para se entender uma exploração extrema como um tipo de tipo de escravização. Para Conforti (2017), a complexidade do tema não está presente apenas na coerção física ou um cerceamento de liberdade explicito, mas está também presente na situação de vulnerabilidade socioeconômica, do aliciamento, da jornada exaustiva, das condições precárias e degradantes de trabalho, do atentado contra a dignidade humana e na ausência de políticas públicas e macroeconômicas voltadas a geração de emprego.

\footnotetext{
${ }^{2}$ FIRME, 2005.
} 


\subsection{Mundo}

Na história da humanidade, não faz muito tempo que gozamos de um mundo de combate à escravização e ao cerceamento da liberdade, revelando-se, portanto, como um processo contemporâneo, já que “a história de Liberdade e da igualdade são recentes, algo que ganhou corpo no século XVII" (FIGUEIRA, 2018, p.24). Destarte, as legislações, convenções e tratados internacionais e locais que tipificam e tratam esse tipo de exploração extrema como ilegal e tentam coibi-la são relativamente recentes. Em 1930, em Genebra, foi elaborada pela Organização Internacional do Trabalho - OIT, na sua Conferência Geral, a Convenção 29, que atesta que o trabalho forçado deve ser combatido e que este fere os direitos humanos. Já em 1959, cria-se a Convenção 105, que é complementar a esta no trato sobre o Trabalho Forçado ou Obrigatório.

As legislações que inibem e coíbem as práticas de trabalho análogo ao de escravo nos diversos países são pautadas nas supracitadas Convenções 29 e 159 da OIT, nos artigos $4^{\circ}$ e $5^{\circ}$ da Declaração Universal dos Direitos Humano (1948) - que proíbe escravidão, tortura e práticas degradantes durante a jornada de trabalho, na Convenção Americana sobre Direitos Humanos (1969) e no Protocolo de Palermo(2003), conhecido como "Protocolo Adicional à Convenção das Nações Unidas contra o Crime Organizado Transnacional Relativo à Prevenção, Repressão e Punição do Tráfico de Pessoas, em Especial Mulheres e Crianças", este último fora incorporado à legislação brasileira em 2004.

Dentro do contexto de disputa política e de debate sobre o tema, a nomenclatura dada a esse fenômeno é de extrema relevância, já que é a partir dela que se desenham as leis, as formas de repressão e o enfrentamento a esse crime em âmbito internacional ou local. Posto isso, os termos mais utilizados para expressar esse tipo de exploração são trabalho forçado, escravidão contemporânea, formas de redução à condição análoga à de escravo e outros (LACERDA; TOSTES; CANTELLI, 2018). De acordo com Timóteo (2015), esses termos são uma sinalização ou marcação de diferenciação entre o trabalho escravo praticado no século XIX e o que se tem praticado atualmente, ao mesmo tempo em que se reportam aos danos provocados às pessoas subjugadas por esse tipo de exploração extrema no contexto da ordem jurídica atual.

A OIT (1959) emprega o termo 'trabalho escravo contemporâneo', por entender que há práticas contemporâneas de escravidão, podendo ser estas o tráfico de pessoas, o trabalho infantil, o trabalho forçado direto e outras. Já o termo adotado no Brasil é trabalho análogo ao de escravo, sendo sua legislação embasada nesta terminologia, já que se entende não ser necessária a coerção direta para tipificar a submissão da pessoa humana a essa forma extrema de abuso. 
Conforti (2017) acredita que o termo trabalho análogo ao de escravo, adotado no Brasil, é mais abrangente que os utilizados pela OIT nas suas convenções, pois traz uma proteção maior e evidência as múltiplas faces utilizadas para a exploração extrema do trabalhado nas condições degradantes e na jornada exaustiva.

Para Filgueiras e Sales (2015) as condições e relações de trabalho são os atributos fundamentais que caracterizam o análogo ao de escravo e o diferencia da época da escravidão moderna, pois os meios de coerção são distintos, bem como a legislação. Portanto, o ato de controlar o ir e vir e a imposição de violência física tornam-se desnecessárias, já que o capital coage de forma mais impessoal por meio do mercado de trabalho.

Logo, a coerção via mercado de trabalho facilita a submissão do trabalhador a condições aviltantes, que atenta à dignidade humana e que são percebidas nas fiscalizações e resgates do GEFM, ao constatar que os trabalhadores bebiam água envenenada por agrotóxico, viviam em alojamentos de lonas, tinhas salários retidos, atrasos ou não o recebiam, ausência de banheiros, inexistência de locais para refeição, fornecimento de comida estragada, entre outras. (CONFORTI, 2017).

De acordo com dados levantados pela Fundação Walk Free (2018), a partir de uma pesquisa conjunta com a OIT e a Organização Internacional para as Migrações (OIM), que utiliza o conceito de coerção direta como característica principal de trabalho escravo contemporâneo, cerca de 40,3 milhões de pessoas em todo o mundo foram vítimas da escravidão contemporânea em 2016. Segundo o documento, o perfil das pessoas submetidas à escravidão é constituído de aproximadamente $71 \%$ mulheres e $29 \%$ homens, sendo que cerca de 25 milhões, do total, estavam sob condições de trabalho escravo.

Ainda de acordo com o Índice Global da Escravidão, criado pela Fundação Walk Free, em 2016, os cinco países que mais praticam a escravidão contemporânea são, respectivamente: Índia, China, Paquistão, Bangladesh e Uzbequistão. Quando o foco da análise é proporcional à população, os países no topo do ranking são: Coreia do Norte, Uzbequistão, Cambodja, Índia e Catar, como mostram os Quadros 1 e 2.

Quadro 1 - Países que possuem em número absoluto de trabalhadores escravizados

\begin{tabular}{|l|c|c|}
\hline \multicolumn{1}{|c|}{ País } & $\mathrm{N}^{\circ}$ de Pessoas (milhões) & \% da População \\
\hline Índia & 18,4 & 1,4 \\
\hline China & 3,2 & 0,24 \\
\hline Paquistão & 2,4 & 0,013 \\
\hline Bangladesh & 1,5 & 0,01 \\
\hline Uzbequistão & 1,2 & 4 \\
\hline Coreia do Norte & 1,1 & 4,4 \\
\hline
\end{tabular}

Fonte: Walk Free Foundation, 2018.elaboração da própria autora, 2019.

Nota: Walk Free foundation criou esse índice de acordo com o conceito de trabalho forçado da OIT. 
Quadro 2 - Os cinco países com o maior percentual de trabalhadores escravizados

\begin{tabular}{|l|c|c|}
\hline \multicolumn{1}{|c|}{ País } & $\begin{array}{c}\mathrm{N}^{\circ} \text { de Pessoas Resgatadas em } \\
\text { Trabalho Forçado (em } \\
\text { milhões) }\end{array}$ & $\%$ da População \\
\hline Coreia do Norte & 1,1 & 4,4 \\
\hline Uzbequistão & 1,2 & 4 \\
\hline Cambodja & 0,257 & 1,6 \\
\hline Índia & 18,4 & 1,4 \\
\hline Catar & 0,303 & 1,4 \\
\hline
\end{tabular}

Fonte: Walk Free Foundation, 2018, elaboração da própria autora,2019.

\subsection{Brasil}

Desde 1888, no Brasil foi abolido legalmente o trabalho escravo. Porém não significa que na prática a abolição tenha ocorrido e esse tipo de exploração tenha deixado de existir, ou seja, ainda é praticado no país, em suas diversas regiões e municípios. O trabalho análogo ao de escravo é resquício da escravidão praticada no Brasil por mais de três séculos e abolida há um pouco mais de cem anos. Para Oliveira et al (2015, p. 582) “o trabalho escravo é uma prática execrável que se mantém no modo de produção capitalista. Herança na condição de colonial do Brasil.".

Para Rezende e Rezende (2013), não houve uma imediata adequação legislativa e jurídica das normas brasileiras em relação às internacionais de enfrentamento às formas de exploração extrema, e "o Brasil demorou bastante a incorporar em seu ordenamento jurídico as normas internacionais que repelem a escravidão e o trabalho em condições análogas às de escravo" (REZENDE; REZENDE, 2013, p.07).

No entanto, o Estado brasileiro, para se adequar às normas internacionais e enfrentar esse tipo de extrema exploração do trabalhador, em 1940 cria o artigo 149 do Código Penal - decretolei 2848/40, que categorizava o trabalho análogo ao de escravo apenas como crime. Esse artigo foi alterado em 2003, via Lei 10.803, e passa a tipificar o que é o trabalho análogo ao de escravo, dando um conceito mais amplo do que seria o trabalho análogo ao de escravo e ao mesmo tempo em que amplia as medidas que visam proteger e indenizar financeiramente os trabalhadores expostos a esse tipo de exploração extrema e as penalidades a serem aplicadas aos empregadores infratores. Para Rezende e Rezende (2013), esse artigo elucida e discrimina o que é o trabalho análogo ao de escravo, deixando de forma explicita as condições em que ocorre, além de suas possíveis penalidade a serem aplicadas a quem o praticar. 
Essas quatro características podem vir a se apresentar isoladas ou em conjunto, o que é o grande cerne de disputa entre empresários criminosos e a justiça brasileira. Aqueles tentam desqualificar o trabalho análogo ao de escravo, alegando que esses quatro acontecimentos devem ser notificados juntos para se caracterizar o crime. Diferentemente, o Ministério Público do Trabalho e a legislação afirmam que não há essa necessidade de simultaneidade de características. Não é necessária a coerção direta individual para ser tipificado como crime ou ser identificado com trabalho análogo ao de escravo, isso diferencia a legislação brasileira das de âmbito internacional, como ratificam Filgueiras (2015) e Conforti (2017).

No artigo 149 a coerção indireta está expressa no trabalho degradante e na jornada exaustiva. Conforti (2017) explica que o trabalho degradante afeta a dignidade humana ao submeter o trabalhador à situação aviltante, ao ignorar a sua humanidade, ao promover uma desonra, ao expor este trabalhador a situações de risco de morte e dano à saúde. Já a jornada exaustiva é mais que a extrapolação da carga horaria de 8 h diárias, é também a alta intensidade ao trabalho, é o exaurir o trabalhador através da extensão demasiada e sem quaisquer garantias de remuneração ou descanso, o que infringe as leis nacionais e os direitos humanos. Para Filgueiras (2016), exceto os capitalistas, os demais da população são obrigados a vender sua força de trabalho e devido à natureza compulsória de reproduzir riqueza abstrata, o capital não reconhece limites ao expropriar de forma extrema a força de trabalho, inclusive a física, e o trabalhador, mesmo gozando de uma liberdade individual, pode se submeter a condições diversas de exploração extrema.

Segundo dados do Ministério Público do Trabalho - MPT (2018), desde 1995 mais de 52 mil trabalhadores foram libertados de trabalho análogo ao de escravo no território brasileiro. $\mathrm{O}$ Gráfico 1 demonstra o número de resgatados e operações de resgates no Brasil ao longo das duas últimas décadas. É possível perceber que há uma queda significativa no número de fiscalização, de cerca de 50\%, nos últimos quatro anos, e, por conseguinte, no número de resgatados, o que demonstra que não há uma queda no uso criminoso de pessoas submetidas a trabalho escravo contemporâneo. Outra análise possível é que a aludida queda pode ser um reflexo da tentativa de sucateamento e de desestruturação dos órgãos de enfrentamento a esse tipo de crime contra os trabalhadores. 
Gráfico 1 - Relação resgatados por fiscalização, Brasil (2000-2018) (Em \%)

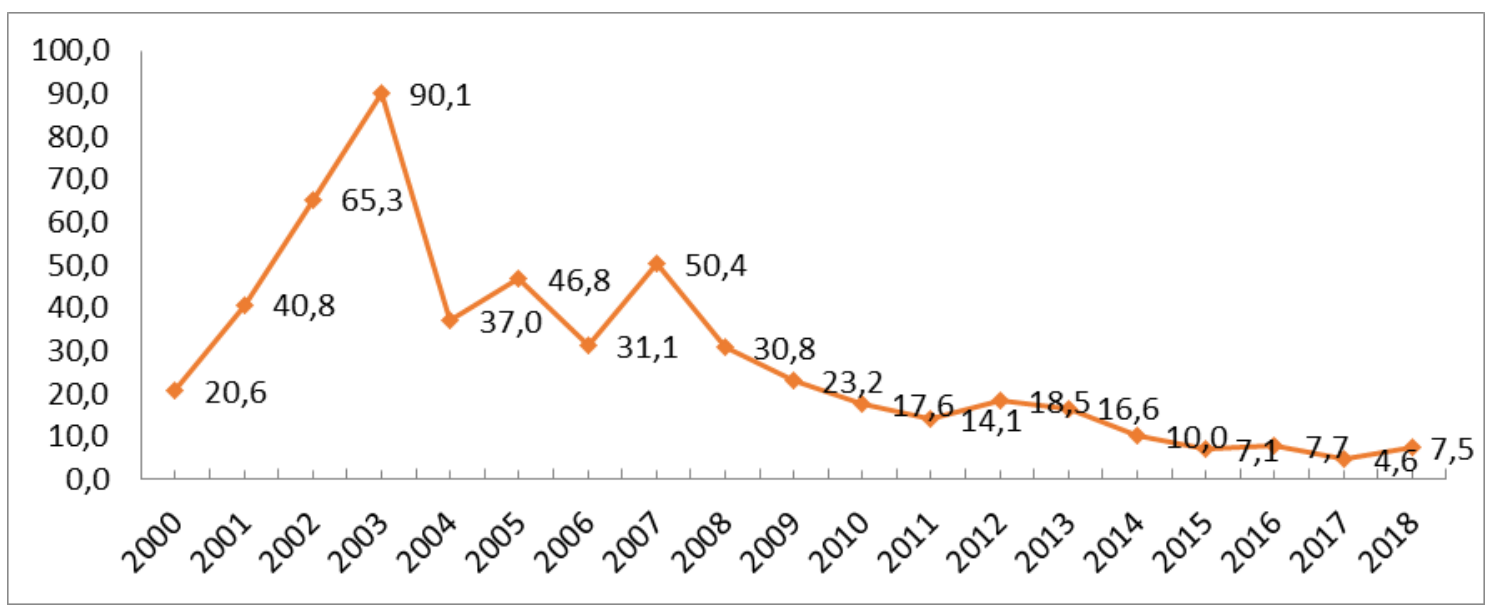

Fonte: SIT, 2019, elaboração da própria autora, 2019.

De acordo com os dados do Observatório Digital do Trabalho Escravo no Brasil (2019), no país, entre 2003 a 2018, foram resgatados no Brasil 45.028 mil trabalhadores, com média de 2.815 trabalhadores por ano. O estado brasileiro em que mais houve resgate de trabalhadores foi o Pará, cerca de 22,3\% do total dos casos, seguido de Mato Grosso 9,8 e Goiás 8,8. Em relação à origem, 22,3\% dos resgatados são naturais do Maranhão, 9,9 da Bahia e 8,6 são de Minas Gerais.

Para Kalil e Ribeiro (2015), no Brasil, as políticas públicas voltadas ao combate ou inibição do trabalho análogo ao de escravo possuem dois aspectos: i) repressivo; e ii) assistencialpreventivo. O de aspecto repressivo é de caráter fiscalizatório e punitivo e teve início em 1995, com a criação do Grupo Especial de Fiscalização Móvel (GEFM), responsável por fiscalizar estabelecimentos denunciados, realizar constatação da submissão do trabalhador às condições similares a de escravo e autuar o infrator.

Outro exemplo de política de caráter repressivo que tornou-se um essencial instrumento na tentativa de combate à prática ilícita de mão de obra é a chamada "Lista Suja", aprovada em 2004, por meio da portaria n. 540 (MTE), que inclui e expõe o nome de empregadores que foram autuados por prática de análogo ao de escravos após decisão administrativa. Por dois anos os nomes dos infratores são inclusos em uma lista de diversos órgãos públicos; depois deste prazo, a exclusão desses nomes pode ocorrer, desde que os envolvidos não reincidam nas irregularidades e tenham realizado o pagamento e quitação das multas advindas do ato ilegal e de débitos trabalhistas e previdenciários. (REZENDE; REZENDE, 2013).

Já as de aspecto assistencial-preventiva, objeto de análise deste artigo, são as políticas públicas que utilizam instrumentos socioeducativos e a formação profissional voltada para o mercado de trabalho, como é o caso do Projeto 'Ação Integrada', e têm como público-alvo os 
trabalhadores resgatados e a pessoas consideradas vulneráveis. Essa, em específico, possui a finalidade de evitar que esse grupo seja submetido a prática extrema de exploração ou que retornem à situação análoga à de escravo,

Ressalte-se, ainda, que a partir de 2003, todos os trabalhadores libertados da condição análoga à de escravos ou de trabalho forçado são imediatamente incluídos no sistema de concessão de seguro-desemprego. Isso porque a lei $\mathrm{n}^{\circ}$ 10.608, de 20 de dezembro de 2002, ao acrescentar o artigo $2^{\circ}-\mathrm{C}$ à lei do seguro-desemprego, passou a garantir ao trabalhador o pagamento de um salário mínimo para aqueles que são assim identificados e resgatados pelas ações do MTE. Na mesma lei, estabelece-se que o trabalhador deve ser encaminhado ao SINE (Sistema Nacional de Emprego), pelo Ministério do Trabalho e Emprego, para qualificação profissional e recolocação no mercado de trabalho. (REZENDE; REZENDE, 2013, p.11).

As etapas I e II do Plano Nacional para a Erradicação do Trabalho Escravo, respectivamente, foram criadas em 2003 e 2008, com o intuito de consolidar o enfrentamento ao trabalho análogo ao de escravo, por meio de melhorias nas estruturas e ferramentas de atuação contra esse tipo de crime, e promoção de ações que visam melhorar as condições dos trabalhadores resgatados e vulneráveis, para que estes não retornem a esse tipo de prática.

Segundo dados de uma pesquisa divulgada pela Organização Internacional do Trabalho (OIT, 2018), dentre os 35.341 trabalhadores resgatados no país, entre 2003 a 2017, 613 destes são reincidentes, ou seja, 1,73\% foram submetidos à condição análoga ao de escravo no mínimo em dois momentos e houve registro dessa infração. Uma possível explicação desse fenômeno é o fato da condição de vulnerabilidade vivenciada por esses trabalhadores, que em muitos casos só conhecem essa realidade de exploração extrema e, comumente, tem inicio na infância e persiste por toda uma vida adulta e contribui para o aprofundamento da situação de extrema precariedade e até a miserabilidade (DELGADO; MIRAGLIA, 2018).

De acordo com a OIT (2011), fatores como a falta de acesso a políticas públicas educacionais, de transferência de renda, e outras, bem como a dificuldade em obter trabalhos dentro de sua cidade, contribuem para a vulnerabilidade dos trabalhadores, o que os expõem ao aliciamento e à exploração mais de uma vez. Também é importante levar em consideração outros elementos de complexidade socioeconômica e histórica por trás dessa fragilidade e consequente vulnerabilidade dos trabalhadores. Nesse sentido:

O fato de haver, na sociedade brasileira, indivíduos que estão na situação de miséria absoluta, favorece, enormemente, não só a indução das pessoas pobres a aceitar serviços que subtraem toda e qualquer dignidade e liberdade dos trabalhadores, mas também a reincidência destes levados pelo desespero de uma vida extremamente precária que os conduzem às condições análogas à de 
escravo. Muitas vezes, os escravizados que foram resgatados retornam, novamente iludidos por agenciadores, à situação de exploração e de impotência. (REZENDE; REZENDE, 2013, p.19)

Os dados que indicam a reincidência de trabalhadores resgatados em situação análoga ao de escravo são subdimensionados no Brasil (OIT, 2018), já que esses são obtidos através do seguro desemprego, quando solicitado pelo trabalhador. Segundo levantamento da Organização Internacional do Trabalho (2018) a probabilidade de um trabalhador analfabeto ser resgatado mais de uma vez é o dobro dos que possuem ensino fundamental completo. A reincidência é uma realidade, mas nem sempre bem mensurada e que demonstra que apesar de ter havido avanços no enfretamento, a vulnerabilidade socioeconômica do trabalhador ainda persiste.

Como já supracitado, as políticas públicas desenvolvidas no Brasil que possuem uma natureza assistencial-preventiva e tem o trabalhador resgatado como seu público-alvo são duas - a concessão do seguro-desemprego e o Projeto Ação Integrada - PAI. Na primeira, de caráter assistencial e implementada em 2002 via alteração da lei 7998/90, os trabalhadores flagrados em situação análoga à de escravidão passam a ter direito a três parcelas do seguro-desemprego, no valor de um salário mínimo cada uma. O Projeto Ação Integrada, criado em 2019 por conjunto de entidades, como MPT, é a segunda política pública, cujo caráter é preventivo e tem o objetivo de dar assistência a trabalhadores resgatados ou considerados vulneráveis por meio de cursos de qualificação profissional, para a melhor reinserção do trabalhador ao mercado de trabalho e também por meio de atividades como sensibilização, mobilização e palestras. Logo, o objetivo da política analisada neste trabalho é de promover o retorno desse trabalhador ao mercado de trabalho, tornando-o empregável, sendo essa a solução encontrada para evitar a exploração extrema do trabalho.

O PAI foi realizado no Mato Grosso, entre os anos de 2009 a 2017, e segundo os dados deste, foram desenvolvidas atividades de qualificação com 691 pessoas, entre vulneráveis e resgatados (585 vulneráveis e 106 resgatados), em 39 cursos de qualificação profissional, totalizando 739 qualificações, pois alguns trabalhadores fizeram mais de um curso.

A análise dos dados de trabalhadores resgatados qualificados durante a vigência do projeto nesse estado aponta que essas pessoas foram qualificadas em 26 cursos, totalizando 114 qualificações. Dentre estes, 72 trabalhadores foram qualificados no período de expansão econômica $^{3}$ (2009 a 2014), o que representa 67,90\%, e 34 trabalhadores foram qualificados no período de desaceleração da economia (2015 a 2017), o que corresponde a 32,10\%. Com relação

\footnotetext{
${ }^{3}$ De acordo com o Comitê de Datação do Ciclo Econômico (CODACE) da Fundação Getúlio Vargas, o período de crescimento econômico brasileiro correspondeu ao período entre 2002 ao primeiro semestre de 2014, iniciando-se, a partir de então, um período de contração econômica.
} 
aos trabalhadores qualificados no período de expansão da economia, concluiu-se que $81,69 \%$ dos trabalhadores obtiveram emprego formal após a realização do curso oferecido pelo PAI. Entretanto, atualmente, apenas $25 \%$ desses trabalhadores estão formalmente empregados.

No que se refere aos trabalhadores que foram qualificados no período de desaceleração econômica, apenas $64,71 \%$ obtiveram emprego formal após a participação no curso. Atualmente, apenas 35,29\% desses trabalhadores estão formalmente empregados. Portanto, diante dos dados analisados, percebe-se que houve maior empregabilidade no período de expansão econômica.

Observa-se que as políticas públicas adotadas para combate ao trabalho análogo ao de escravo estão ligadas ao mercado de trabalho, seguro-desemprego e qualificação profissional, justamente com o intento de que o trabalhador resgatado ou vulnerável qualificado retornaria ao emprego formal e se afastaria da vulnerabilidade e reincidência. Dessa forma, o que se pensa enquanto solução para enfrentar e combater à exploração do trabalho está no próprio mecanismo que torna viável a exploração do trabalhador, o mercado do trabalho e seus interesses, já que "foram os interesses econômicos ligados à escravidão que permitiram a sua continuidade [...]" (CONFORTI, 2017, p. 01), o que não romperia com esse ciclo vicioso do capital, que é a expropriação ao máximo do trabalhador.

\section{Mercado de trabalho como (de) solução}

3.1 Mercado de trabalho e trabalho análogo ao de escravo

Ao tornar-se o sistema de produção vigente, o capitalismo, ao criar o Mercado, passa a regular a vida econômica e social das pessoas (VIEIRA, 2012). Quase tudo está no Mercado, inclusive o trabalho. O mercado de trabalho emergiu nesse contexto e torna-se o mediador "natural" da vida em sociedade, as pessoas são "transformadas" em insumo produtivo, pois põem à venda, no mercado, a sua força de trabalho em troca de uma remuneração e que podem ser descartados ou substituídos a depender da sua escassez ou abundancia (VIEIRA, 2012).

No capitalismo, não há uma igualdade de condições entre o capitalista e o empregado, pois o primeiro é detentor dos meios de produção e do capital, podendo movê-los de acordo com as condições mais favoráveis a aumentar a sua taxa de lucro e a rentabilidade do capital. O trabalhador é um ofertante de força de trabalho e espera ganhar uma remuneração em troca. Diante dessa desigualdade de condições, o capitalista detém um poder maior de barganha e de impor as condições de trabalho e dos salários. Para Marx (2008) o capitalista sujeita o trabalhador as suas exigências devido à capacidade de mobilidade do capital. 
Num mundo globalizado, houve uma reformulação nos termos de exploração do trabalho e de produção; os capitalistas migram o capital para locais que lhes ofereçam possibilidade de maior competitividade. Segundo Timóteo (2015, p. 242), in verbis,

O processo de fabricação em geral ocorre em unidades produtivas instaladas em territórios periféricos que oferecem melhor competitividade; e melhor competitividade muitas vezes significa, nesse contexto, mão de obra barata, por vezes precária e não sindicalizada, bem como pouca regulação e limitada fiscalização laboral e ambiental por parte do Estado. (TIMÓTEO, 2015, p. 242).

O Estado aparece, nesse contexto, como meio regulador do mercado de trabalho para o capital, por intermédio de políticas públicas, que, nesta ótica, buscam uma maior "flexibilização" desse mercado, a fim de aumentar a potencialidade da produção e alinhando os incentivos dos empregadores e trabalhadores (TELES, 2017).

As políticas econômicas de emprego sofreram uma inversão de objetivos desde o final do século passado, de forma que alcançar o pleno emprego foi substituído pela plena empregabilidade, ou seja, tornar-se empregável tornou-se essencial para o mercado de trabalho em detrimento da expansão deste mercado (TELES, 2017). Para esse autor, as teorias neoclássicas, a partir de suas questões microeconômicas focadas apenas no mercado de trabalho, substituíram as políticas macroeconômicas de emprego, pois a empregabilidade do trabalhador, alcançada através de um mercado de trabalho mais eficiente e flexível, tornou-se fator mais importante que as políticas de emprego voltadas para o crescimento desse mercado.

Pode-se entender, com a crítica feita por este autor a essa nova lógica do mercado de trabalho, que há uma mudança de posições entre o empregador e o empregado, recaindo para o último o peso de estar ou não empregado, ou de ser suscetível ou não ao trabalho análogo ao de escravo, pois ser empregável seria a variável chave para não ser explorado ao extremo.

Para Filgueiras (2015) o mercado de trabalho é o instrumento de coerção indireta e coletiva do capital sobre os trabalhadores. Portanto, entende-se que o mercado de trabalho, dentro de lógica capitalista vigente, é a coerção específica e "invisível" deste modo de produção, que força o trabalhador a se submeter às condições aviltantes e desumanas, não havendo necessidade de coerção direta ou uso de força, (FILGUEIRAS, 2015). Compreende-se que o mercado de trabalho por si só é um mecanismo poderoso de coerção e que vem sendo usado pelos capitalistas como "escudo" protetor para justificar a exploração extrema, à medida que o trabalhador é culpabilizado por não ser empregável e não estar em conformidade com as exigências do mercado. 
A coerção via mercado de trabalho também é identificada pelo Estado brasileiro. De acordo com Filgueiras (2016), ao prevalecer o entendimento, pelas instituições brasileiras, de que o trabalhador ao ser submetido a condições degradantes e também a jornadas exaustivas foi submetido a condições análogas à escravidão, implica que para a tipificação não há necessidade de coerção direta do empregador, como também que o mercado de trabalho opera para submeter, de forma indireta, o trabalhador.

O Estado brasileiro capaz de identificar a coerção indireta do mercado de trabalho sobre os trabalhadores é o mesmo Estado promotor de políticas públicas de enfrentamento ao trabalho análogo à escravidão, via mercado de trabalho. O Projeto 'Ação Integrada' expõe a lógica neoclássica de mercado do trabalho pensada pelo Estado, em que submeter um trabalhador resgatado ou em situação de vulnerabilidade a algum tipo de qualificação profissional, tornaria essa pessoa empregável e reduziria a chances dela ser submetida a situação análoga à de escravidão.

Nesse sentido, é importante atentar para a influência que uma determinada teoria em posição hegemônica desempenha na forma como o Estado atua e participa no processo de formulação de políticas públicas. A percepção da lógica de funcionamento do mercado de trabalho a partir de teorias ortodoxas, por exemplo, a qual pode ser relacionada com a maioria das políticas levantadas durante este estudo, tem sustentado, sobretudo ao longo das últimas décadas, as análises em torno de questões microeconômicas. Por outro lado, tal assertiva não significa que a adoção de políticas públicas no âmbito do mercado de trabalho se restringe apenas ao mainstream.

Ao analisar as políticas macroeconômicas de expansão do mercado de trabalho, principalmente anticíclicas, há uma possibilidade de redução, mesmo que pequena, da prática de trabalho análogo ao de escravo dentro da lógica do emprego formal em que há uma disputa por mão de obra, no sentindo de ocupação das vagas para aumento da produção. Políticas macroeconômicas de caráter mais heterodoxo poderiam contribuir para uma possível redução desse tipo de exploração extrema. Isso devido ao papel fundamental que o Estado possui nessas políticas, sobretudo a partir da promoção da expansão do emprego através do investimento governamental. Keynes (2012) acredita que o governo tem que agir com políticas fiscais anticíclicas e assim promover o aumento nos postos de trabalho, o que promoveria uma demanda efetiva sempre muito próxima ao pleno emprego. Kalecki $(1954 ; 1983)$ pensava que os investimentos governamentais eram muito importantes para o desenvolvimento de uma economia e que deveriam ser feitos a partir da tributação dos lucros e dessa forma tornar menos desigual a sociedade. 
Dentro da lógica de disponibilidade de emprego, como um item que pode contribuir para diminuir a exploração extrema dos trabalhadores, Kalecki (1954; 1983) apontava políticas macroeconômicas que estimulem a demanda efetiva e expansão do emprego, principalmente em economias em desenvolvimento. Para esse autor, o governo tem papel fundamental na contração e expansão do mercado de trabalho, sendo o principal instrumento de fomento do emprego numa crise econômica, por exemplo. Isto porque o investimento governamental provocaria a ocupação da capacidade ociosa do país, mesmo que, em um primeiro momento, se der através de uma diminuição da produtividade do trabalho. Ainda assim, o principal objetivo seria alcançado, o de promover a maior ocupação da mão de obra disponível em países em desenvolvimento, que em geral é bem ampla.

O Estado ao elaborar políticas públicas para inibir a prática de trabalho análogo ao da escravidão, não leva em consideração políticas macroeconômicas de expansão do mercado de trabalho, apesar desse mercado ser o instrumento usado para tentar diminuir a vulnerabilidade socioeconômica dos trabalhadores, e vem elegendo elementos da microeconômica propagada pelas teorias neoliberais como suficientes, como a empregabilidade ou a chamada qualificação profissional. Isso ocorre porque o governo não considera a flutuação econômica como fator importante na oferta de vagas de emprego. O movimento contracionista e expansionista da economia é o que determina a inserção ou não do trabalhador no mercado formal de trabalho, não somente o fato de ter ou não uma qualificação, ou seja, ser empregável ou não torna-se irrelevante frente a um mercado de trabalho sujeito a uma flutuação econômica.

Apesar disso, o caráter anticíclico das políticas macroeconômicas heterodoxas, em que se pretende ter um nível elevado para o pleno emprego, e, ao mesmo tempo, estimular a demanda efetiva, faz com que haja uma maior oferta de emprego, uma geração de postos de trabalho mesmo em contração econômica, o que poderia contribuir com uma menor exposição do trabalhador a situação de exploração extrema.

Por conseguinte, o que se quer destacar aqui é que pensar políticas públicas de combate ao trabalho escravo que visam à empregabilidade como fator de resposta a essa prática é pensar políticas que alimentam o próprio problema, uma vez que o mercado de trabalho induz a essa falsa interpretação. Além de que políticas microeconômicas de mercado de trabalho, por exigências do próprio mercado, não se traduzem em uma solução de fato para o combate ao trabalho análogo.

Políticas macroeconômicas de expansão do emprego podem ser uma alternativa para possível redução da exposição do trabalhador a esse tipo de situação empregatícia. Ainda que 
essas políticas não atinjam a raiz do problema, a vulnerabilidade, elas podem promover algum obstáculo à expansão e ao acirramento do problema.

\section{Considerações}

O trabalho análogo ao de escravo é fato mundial. De acordo com a sua legislação e do conceito empregado, cada país elabora políticas de enfrentamento visando inibir essa prática. As Convenções da OIT, no 29 e 105, têm papel fundamental na elaboração dessas políticas, pois norteiam o que deve ser entendido como prática de exploração extrema do trabalho.

No Brasil, o artigo 149 tipifica o que é a prática de trabalho análogo ao de escravo e esse entendimento foi construído como base nas convenções supracitadas e em outros protocolos internacionais, como o de Palermo.

A partir desse entendimento em lei, o país vem criando vários instrumentos de combate a esse crime. Para tanto, criou políticas públicas de caráter repressivo - GEMF, 'Lista Suja', o pagamento de indenização, dentre outras condutas, que têm como objetivo inibir a prática penalizando o infrator, além das políticas de caráter assistencial-preventivo - concessão de três parcelas do Seguro Desemprego e o Projeto Ação Integradas- que têm como objetivo dar assistência ao trabalhador.

As políticas públicas de caráter assistencial-preventivo estão relacionadas ao mercado de trabalho, pois o modo como o Estado enxerga a solução para quebrar o ciclo de vulnerabilidade do trabalhador é por esse mercado, por meio da qualificação e da chamada empregabilidade. Desta maneira, o Estado não percebe que o próprio mercado de trabalho seria o cerne do problema, pois culpabiliza o trabalhador pelo ato de ser explorado e ignora o fato da coerção indireta deste mercado.

Tratar o mercado de trabalho e a ideia da empregabilidade como soluções para esse problema é um equívoco, pois ignora o fato desse mercado e da geração de emprego, dentro de políticas neoclássicas, serem dependentes do ciclo econômico. Um país que está num ciclo econômico de expansão terá uma expansão no mercado de trabalho e absolverá o máximo de força de trabalho, sendo esta qualificada ou não. Se este mesmo país estiver num ciclo contracionista, haverá um encolhimento do mercado de trabalho e uma parcela significativa da população estará desempregada e se submetendo a trabalhos informais e a exploração extrema mesmo, sendo esse trabalhador "empregável" ou não.

Os dados levantados sobre o PAI mostram que, apesar de ter um caráter assistencialpreventivo, a política pública não teve êxito na "quebra" da situação de vulnerabilidade dos 
trabalhadores. Uma explicação para tal deve-se às suas características e ao objetivo principal, voltados à máxima de qualificar para empregar, sendo que na realidade fática a maioria dos trabalhadores qualificados está desempregada e dependente de uma oportunidade de emprego. Tratar o mercado de trabalho como ferramenta de diminuição da fragilidade socioeconômica das pessoas é muito restrita e inócua.

Faz-se necessário repensar as políticas macroeconômicas de expansão de emprego e as políticas públicas de combate ao trabalho análogo ao de escravo no Brasil. O Estado tem papel fundamental na promoção e elaboração dessas políticas, mas é necessária a mudança de mentalidade. O mercado de trabalho pode ser usado como instrumento para reduzir o número de trabalhadores em situação análoga à de escravidão, desde que não seja via mercado de trabalho neoclássico, que é o atual formato dessas políticas.

Além de políticas macroeconômicas de caráter heterodoxo, é necessário pensar e formular políticas públicas que deem autonomia aos trabalhadores que já foram submetidos ou estão suscetíveis a esse tipo de exploração. Para muitos estudiosos da temática, a reforma agrária e as políticas de fomentação a produção agrícola e pecuária para a agricultura familiar seria um instrumento eficaz contra a pauperização, o que romperia com o ciclo de exploração que, em muitos casos, se inicia no êxodo.

\section{Referências}

ALMEIDA, A.A. Trabalho escravo: a dignidade dilacerada pelo capital. Revista Filosofazer. Passo Fundo: no 35, pp 115-140, 2010.

BRASIL. Ministério da Economia. Secretaria de Inspeção do Trabalho (SIT). Resultados das Operações de Fiscalização para Erradicação do Trabalho Escravo. Brasilia: Disponível em: $<$ http://trabalho.gov.br/fiscalizacao-combate-trabalho-escravo/resultados-das-operacoes-defiscalizacao-para-erradicacao-do-trabalho-escravo>. Acessado: 14 nov.2018.

Ministério da Economia. Secretaria de Inspeção do Trabalho (SIT). Cadastro do Empregador. Brasília: Disponível em: <http://trabalho.gov.br/images/Documentos/ cadastro_empregadores_out.pdf.> Acessado: 23 de nov. de 2018.

Lei no 10.803, de 11 de dezembro de 2003 que altera o Art. 149 do Decreto-Lei no 2.848, de 1940. Código Penal, para estabelecer penas ao crime nele tipificado e indicar as hipóteses em que se configura condição análoga à de escravo. Disponível em: < http://www.planalto.gov.br/ ccivil_03/LEIS/2003/L10.803.htm>. Acesso em: 24 jul. 2018.

CONFORTI, L. P. A interpretação do conceito de trabalho análogo ao escravo no Brasil: o trabalho digno sob o prisma da subjetividade e a consciência legal dos trabalhadores. Publicação em congresso. XXVI Encontro Nacional do CONPEDI. (pp.160-178), 2018, Florianópolis. Anais... Florianópolis: CONPEDI. Disponível em: 
https://www.conpedi.org.br/publicacoes/roj0xn13/hots52m3/3j49L833n6n8bR0v.pdf. Acessado: 23 nov. de 2018.

DELGADO, Gabriela N. e MIRAGLIA, Lívia M. M. 130 anos da Lei Áurea no Brasil: A regulamentação de uma representação simbólica de liberdade humana. In: MIRAGLIA. L. M. M.; SOUZA, A. A. M; e JR, J. E. R. C. Trabalho escravo contemporâneo - "desafios e perspectivas. São Paulo: LTr editora ltda, 2018.

FIGUEIRA, R. Z. A Busca não acaba nunca: conversando sobre à escravidão contemporânea. In: MIRAGLIA. L. M. M.; SOUZA, A. A. M; e JR, J. E. R. C. Trabalho escravo contemporâneo - “desafios e perspectivas. (pp. 24-29). São Paulo. LTr editora ltda, 2018.

FILGUEIRAS, V. e SALES, J. Trabalho análogo ao escravo no Brasil: natureza do fenômeno e regulação. Revista da ABET, v. 12, n.2. 29-47, 2013.

FILGUEIRAS, V. Trabalho análogo ao escravo e o limite da relação de emprego: natureza e disputa na regulação do Estado. In: Org. PRADO, A. A.; GALVÃO, E. M.; e FIGUEIRA, R. R. A universidade discute a escravidão contemporânea. Rio de Janeiro: Mauad X, 2015.

Terceirização e trabalho análogo ao de escravo: estreita relação na ofensiva do capital. In: Org. TEIXEIRA, M. O.; ANDRADE, H. R; e COELHO E.D. Precarização e terceirização: faces da mesma realidade. São Paulo: Ed. do Sindicato dos Químicos, 2016.

FIRME, T. B. O caso José Pereira: a responsabilização do Brasil por violação de direitos humanos em relação ao trabalho escravo. 87 f. Trabalho de conclusão de curso (Graduação de direito)-Centro Universitário de Brasília, Brsília, 2005.

FUJIWARA, L. e SILVA, P. R. Ação Integrada e o perfil sócio-produtivo de trabalhadores resgatados de condição análoga à escravidão no estado de Mato Grosso. Revista Direitos, trabalho e política social. 2(3). (pp.118-136), 2016).

GUARINELLO, N. L. Escravos sem senhores: escravidão, trabalho e poder no Mundo Romano. Revista Brasileira de História. São Paulo, v. 26, nº 52, p. 227-246, 2006.

KALECKI, Michael. (1954). Teoria da dinâmica econômica. São Paulo: Abril Cultura, 1983. (Coleção Os Economistas).

KALIL, R. B. e RIBEIRO, T. G. A. Trabalho escravo contemporâneo e proteção social. Revista Direitos, trabalhos e política social. 1(1). (pp.15-38.), 2015.

KEYNES, J. M. Teoria geral do emprego, do juro e da moeda. (1 $1^{\text {a }}$ ed.) São Paulo: Saraiva, 2012.

KOWARICK, Lúcio. Capitalismo e marginalidade na América Latina. (1ª ed.) Rio de Janeiro: Paz e Terra, 1975.

LACERDA, C., TOSTES L. F.D e CANTELLI P. O. Um Olhar Contemporâneo do Trabalho Escravo: a Luta Continua In: MIRAGLIA. L. M. M.; SOUZA, A. A. M; e JR, J. E. R. C.

Trabalho escravo contemporâneo - "desafios e perspectivas. São Paulo. LTr editora ltda, 2018. 
MAESTRI, M. O Escravismo Colonial: A revolução Copernicana de Jacob Gorender, a Gênese, o Reconhecimento, a Deslegitimação. São Leopoldo RS. Cadernos IHU Ano 3 - N ${ }^{\circ}$ 13, 2005.

MARX, Karl. Trabalho Assalariado e Capital. (8a ed.) São Paulo, Global, 2008. OLIVEIRA, G. G, GERMANI, G. I, COUTINHO, E. S. e ARAÚJO, T. N. Trabalho análogo ao de escravo: ordenamento jurídico e estruturas de poder. In: Org. PRADO, A. A.; GALVÃO, E. M.; e FIGUEIRA, R. R. A universidade discute a escravidão contemporânea. Rio de Janeiro: Mauad X, 2015.

OBSERVATÓRIO DIGITAL DE TRABALHO NO BRASIL. Disponível em: < https:// smartlabbr.org/trabalhoescravo>. Acessado: 26 out. de 2018.

ORGANIZAÇÃO INTERNACIONAL DO TRABALHO. C029 - Trabalho Forçado ou Obrigatório. Disponível em: < https://www.ilo.org/brasilia/convencoes/WCMS_235021/ lang-pt/index.htm>. Acesso: 23 set. 2017.

C105 - Abolição do Trabalho Forçado. Disponível m:<https://www.ilo.org/ brasilia/convencoes/WCMS_2351 95/lang--pt/index.htm>. Acesso: 23 set. 2017, 1959.

Perfil dos principais atores envolvidos no trabalho escravo rural no Brasil. OIT, 2011. Disponível em:<https://www.ilo.org/brasilia/publicacoes/WCMS_227533/ lang--pt/index.htm>. Acessado: 13 set de 2017.

. Em 15 anos, 613 trabalhadores foram resgatados pelo menos duas vezes da escravidão. 2018. Disponível em: < https://www.ilo.org/brasilia/noticias/WCMS_6168 12/lang--pt/index.htm>. Acessado: 26 ago. de2018.

PROJETO AÇÃO INTEGRADA. Movimento Ação Integrada. 2009.Disponível em: <http://www.acaointegrada.org/>. Acessado: 27 ago. de 2017.

REZENDE, M. J; e REZENDE, R. C. As dificuldades de erradicação do trabalho escravo no Brasil hoje e a exposição dos muitos desafios postos ao desenvolvimento humano. Nómadas Revista Crítica de Ciencias Sociales y Jurídicas. Especial: América Latina. Madri, Mediterranean Perspectives, pp.1-24, 2013.

SOUZA, C. Políticas Públicas: uma revisão da literatura. Revista Sociologias, ano 8, n ${ }^{\circ}$ 16, pp. 20-45, 2016.

TELES, N. O trabalho como variável de ajustamento: da teoria à prática. In: SILVA, Manuel Carvalho da.; HESPANHA, Pedro; e CALDAS, José. O Trabalho como variável de ajustamento: da teoria à prática.). 1. Lisboa: Ed.Lisboa Almedina, 2017.

TIMÓTEO, G. L.S. Trabalho em condições análogas à de escravidão na sociedade de consumo. In: Org. PRADO, A. A.; GALVÃO, E. M.; e FIGUEIRA, R. R. A universidade discute a escravidão contemporânea. Rio de Janeiro: Mauad X, 2015.

TRESPACH, Rodrigo. Histórias não (ou mal) contadas: Escravidão, do ano 1000 ao século XXI. Rio de Janeiro: Harper Collins Brasil, 2018. 
VIEIRA, P. A. As especificidades da mercadoria força de trabalho: Marx revisitado. Acta Scientiarum. Human and Social Sciences Maringá, v. 34, n. 2, p. 193-204, July-Dec. 2012.

WALK FREE FOUNDATION. Índice Global da Escravidão. 2018. Disponível em: $<$ https://downloads.globalslaveryindex.org/ephemeral/GSI-2018_FNL_180907_Digital-smallp-1550414490.pdf>. Acessado: 26 nov. de 2018.

Recebido em: Dezembro de 2019 Aprovado em: Maio de 2020 